\title{
Chylous Ascites in Systemic Lupus Erythematosus (SLE) Patients
}

Vital Da Silva Domingues, Isabel Neves, Susana Garrido, Inês Ferreira, Teresa Mendonça Serviço de Medicina, Hospital de Santo António, Centro Hospitalar do Porto, Portugal

Received: 10/05/2015

Accepted: $25 / 06 / 2015$

Published: $13 / 07 / 2015$

How to cite this article: Da Silva Dominguez V, Neves I, Garrido S, Ferreira I, Mendonça T. Chylous ascites in systemic lupus erythematosus (SLE) patients. EJCRIM 2015;2:doi: 10.12890/2015_000229

Conflicts of Interests: The authors declare that they have no conflicts of interest in this research.

Acknowledgements: The authors declare they had patient's permission for reporting this case report.

This article is licensed under a Commons Attribution Non-Commercial 4.0 License

\section{ABSTRACT}

The gastrointestinal system is commonly implicated in Systemic Lupus Erythematosus (SLE). Ascites, produced by several mechanisms has been reported as a systemic manifestation of lupus, but only rarely as an initial presentation of the disease. Its appearance is often insidious and without abdominal pain. Chylous ascites (such as chyle in the peritoneal cavity) has seldom been reported in SLE. We describe a case of chylous ascites in an SLE patient, reviewing the other published cases, its pathophysiology and its management.

\section{LEARNING POINTS}

- Chylous Ascites in Systemic Lupus Erythematous (SLE) patients is a rare finding that needs an organized approach to exclude other common etiologies.

- Lymphatic obstruction as a result of inflammation may be a plausible explanation of Chylous Ascites formation in SLE patients.

- Chylous Ascites seems to respond well to steroids and have a low relapse incidence.

\section{KEYWORDS}

Chylous ascites, systemic lupus erythematous, gastrointestinal system.

\section{INTRODUCTION}

Systemic lupus erythematosus (SLE) is a multisystemic chronic autoimmune disease. Gastrointestinal system involvement in SLE is commonly reported as vasculitis, malabsorption and protein-losing enteropathy ${ }^{[1]}$. However, any type of presentation may develop at any time of the systemic disease, making its clinical course unpredictable.

Ascites is a systemic manifestation of lupus which includes several mechanisms ${ }^{[1]}$ : hypoalbuminemia produced by nephrotic syndrome in cases of lupus nephritis or protein-losing enteropathy; right heart failure complicating lupus pericarditis; portal hypertension caused by vascular thrombosis in the antiphospholipid syndrome (i.e., thrombosis of the portal veinor Budd-Chiari syndrome). Ascites may also result from inflammatory serositis from the same mechanism as that of pericarditis and pleuritis, with an exudative effusion that is positive for both antinuclear and anti-DNA antibodies. Its appearance is often insidious and painless.

There have been few reports of chylous ascites (i.e. chyle in the peritoneal cavity). The composition of chylous ascites is identical to that of the thoracic duct with a triglyceride 2-8 times higher than plasma and usually greater than $110 \mathrm{mg} / \mathrm{dL}^{[2]}$. We describe a rare case of chylous ascites in a SLE patient.

\section{CASE REPORT}

A 30-year-old female Caucasian presented with abdominal distension, asthenia and pelvic pain. Initial physical exam and laboratory results were unremarkable. She gave 13-year history of SLE diagnosed on the basis of laboratory results (Table 1). Although persistently ANA positive, she had been in remission for 13 years. She had initially presented with pleurisy, photosensitivity and fever that were all well controlled with prednisolone $10 \mathrm{mg} /$ daily, hydroxychloroquine $300 \mathrm{mg} /$ daily, and also a methotrexate $15 \mathrm{mg} /$ weekly dose up until 1 year ago, when it that had been stopped because of hepatotoxity.

On abdominal ultrasound, only a minor peri-caecal lamina of peritoneal liquid was found. On magnetic resonance, there was mild ascites, diffuse parietal and visceral pelvic peritoneal thickening and an inflamed bladder wall. A diagnosis of interstitial cystitis was made and her steroid dose was increased to $20 \mathrm{mg} /$ daily and she was advised to hydrate. 
She was followed-up for 1 year with serial abdominal ultrasounds, which showed bilateral inguinal lymphadenopathy with inflammatory characteristics and progressively increasing ascites.

\begin{tabular}{|c|c|c|c|c|c|}
\hline & Parameters & At SLE diagnosis & At CA diagnosis & Evolution & Reference Value \\
\hline \multirow{33}{*}{ Blood } & Leucocytes & 1750 & 1550 & 790 & 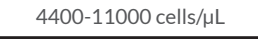 \\
\hline & Hemoglobin & 9.8 & 10.7 & 8.4 & $12.3-15.7 \mathrm{~g} / \mathrm{dL}$ \\
\hline & Neutrophils & 1100 & 320 & 1890 & $1800-7800$ cells $/ \mu \mathrm{L}$ \\
\hline & Lymphocytes & 870 & 310 & 980 & $1100-4800$ cells $/ \mu \mathrm{L}$ \\
\hline & Thrombocytopenia & 16,0000 & 10,0000 & 68,000 & $15,0000-45,0000 \mathrm{plt} / \mathrm{mm} 3$ \\
\hline & Erythrocyte sedimentation rate & 32 & 34 & 32 & $<38 \mathrm{~mm} / \mathrm{h}$ \\
\hline & C-reactive protein & 16 & 24 & 17 & $<6 \mathrm{mg} / \mathrm{dL}$ \\
\hline & Total protein & 6.5 & 7.4 & 6.9 & $6.0-8.0 \mathrm{~g} / \mathrm{dL}$ \\
\hline & $\operatorname{lgG} / \operatorname{lgA}$ & - & $12.4 / 1.25$ & - & $7-16$ and $0.7-4.0 \mathrm{~g} / \mathrm{dL}$ \\
\hline & Albumin & 3.2 & 3.3 & 2.9 & $3.8-4.4 \mathrm{~g} / \mathrm{dL}$ \\
\hline & TGP & 15 & 22 & 12 & $10-36 \mathrm{U} / \mathrm{dL}$ \\
\hline & TGO & 19 & 22 & 18 & $10-30 \mathrm{U} / \mathrm{dL}$ \\
\hline & GTT & 20 & 22 & 18 & $32-104 \mathrm{U} / \mathrm{L}$ \\
\hline & FA & 48 & 62 & 57 & $32-104 \mathrm{U} / \mathrm{L}$ \\
\hline & Creatinine & 0.9 & 0.96 & 0.85 & $0.5-0,9 \mathrm{mg} / \mathrm{dL}$ \\
\hline & Urea & 45 & 59 & 30 & $10-50 \mathrm{mg} \mathrm{d} / \mathrm{L}$ \\
\hline & $\mathrm{C} 3$ & 0.62 & 0.7 & 0.84 & $0.9-1.80 \mathrm{~g} / \mathrm{L}$ \\
\hline & $\mathrm{C} 4$ & 0.04 & 0.12 & 0.21 & $0.09-0.36 \mathrm{~g} / \mathrm{L}$ \\
\hline & Antinuclear antibodies & Positive & Positive & Positive & - \\
\hline & Anti-dsDNA & 125 & 98 & 56 & $<15 \mathrm{U} / \mathrm{ImL}$ \\
\hline & Lupus coagulant & Negative & Negative & Negative & - \\
\hline & Anticardiolipin & - & - & Negative & - \\
\hline & b2-Glicoproteina & - & - & Negative & - \\
\hline & Total cholesterol & - & 174 & - & $<190 \mathrm{mg} / \mathrm{dL}$ \\
\hline & Triglycerides & - & 98 & - & $<140 \mathrm{~g} / \mathrm{dL}$ \\
\hline & Hemoculture & - & Sterile & - & - \\
\hline & Ser Hepatitis B & - & Negative & - & - \\
\hline & Ser Hepatitis C & -- & Negative & - & - \\
\hline & Ser CMW & - & Negative & - & - \\
\hline & Ser Leishmania & - & Negative & - & - \\
\hline & Plasmodium & - & Negative & - & - \\
\hline & HIV & - & Negative & - & - \\
\hline & Quantiferon & - & Negative & - & - \\
\hline Urine & Urine analysis & Normal & Normal & Normal & - \\
\hline \multirow{13}{*}{$\begin{array}{l}\text { Perit on e a I } \\
\text { liquid }\end{array}$} & Triglycerides & - & 289 & - & $110 \mathrm{mg} / \mathrm{dL}$ \\
\hline & Leucocyte & - & 250 & - & Cells/uL \\
\hline & Neutrophils & - & $40 \%$ neutrophils & - & - \\
\hline & Glucose & - & 98 & - & $\mathrm{mg} / \mathrm{dL}$ \\
\hline & Albumin & - & 3.12 & - & $\mathrm{g} / \mathrm{dL}$ \\
\hline & Serum - ascites gradient & - & 1.2 & - & - \\
\hline & Adenosine desaminase & - & 22 & - & $<40 \mathrm{U} / \mathrm{L}$ \\
\hline & Cytological exam & - & $\begin{array}{l}\text { no lupus } \\
\text { no malignant cells }\end{array}$ & - & - \\
\hline & Gram stain & - & Absent & - & - \\
\hline & Stain acid fast bacilli & - & Absent & - & - \\
\hline & Microbio culture & - & Sterile & - & - \\
\hline & ANA & - & Positive & - & - \\
\hline & Anti-SSA & - & Positive & - & - \\
\hline
\end{tabular}


Review of her laboratory data (Table 1) suggested that she might have a lymphoproliferative disease. The patient was submitted to a positron emission tomography that showed an increase in her inguinal lymph nodes and a diffuse moderate ascites along the mesentery, pelvis and perihepatic and perisplenic spaces. Paracentesis was performed, retrieving a milky-appearing turbid liquid that was alkaline, rich in triglycerides (Fig. 1) and contained chylomicrons on electrophoresis but no cytological abnormalities.

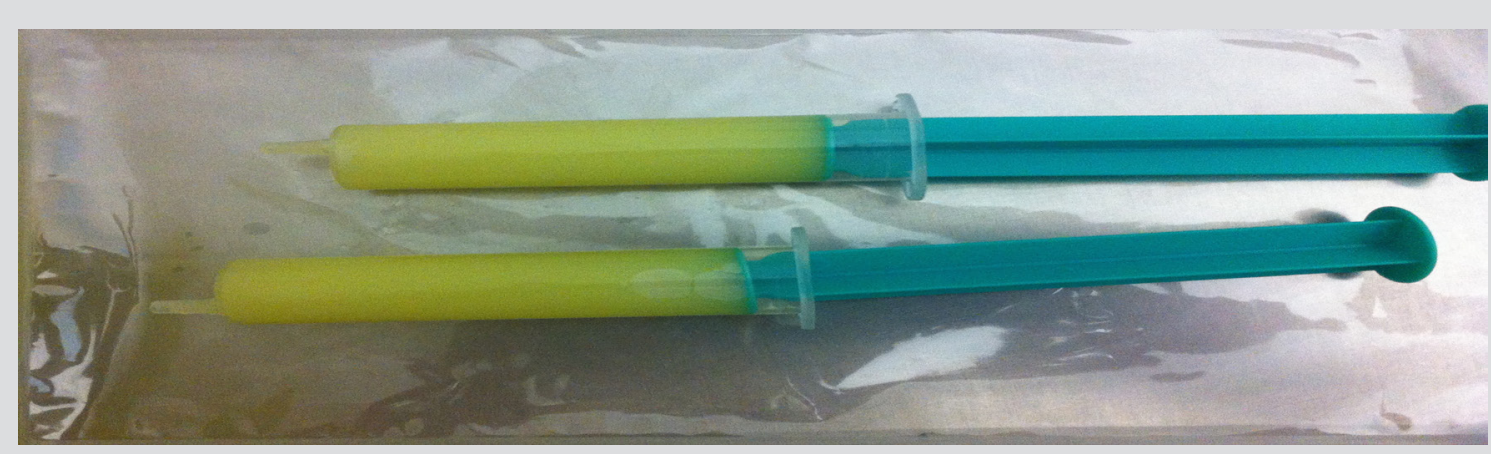

Figure 1: Syringes with chyle peritoneal fluid

An ascites liquid flow cytometry showed a reduced B-lymphocytes percentage (\%) and a normal CD4/CD8 ratio. Immunoblotting analysis of peritoneal effusion was positive for antinuclear antibodies. Follow-up laboratory results showed hypergammaglobulinemia without monoclonal component. A bone biopsy showed normal shaped bone trabeculae; $30 \%$ cellularity; and a myeloid:erythroid ratio 1:1 . Serum tumor markers were all negative, except a mildly elevated CA125 of $92 \mathrm{kU} / \mathrm{L}$ (normal range <35kU/L). Once the common causes of chylous ascites had been excluded she was treated with cyclosporine up to a maximum of $250 \mathrm{mg} /$ day for 1 year, granulocyte-stimulating factors and repeated paracentesis, and maintenance prednisolone $20 \mathrm{mg} /$ daily. During the next 4 years, she continued prednisolone $5 \mathrm{mg} / \mathrm{daily}$ and cyclosporine $150 \mathrm{mg} /$ daily and she underwent monthly paracentesis. Her hematologic changes improved and her clinical condition remained stable.

\section{DISCUSSION}

Chylous ascites is a rare form of ascites most often seen in women, especially those of child-bearing age, and usually in those of non-European descent $^{[1,4]}$. It has previously been reported in SLE as a presenting manifestation of the disease. This the first report of it as a finding late in the course of the disease. A possible mechanism for chylous acites may be lymphadenopathy, which is usually a benign finding in SLE that is commonly seen in young patients with cutaneous involvement and constitutional symptoms ${ }^{[3,5]}$. In our patient, for logistical reasons, we did not perform a lymphoscintigraphy. However, computerized tomography (CT), magnetic resonance imaging (MRI) and positron emission tomography (PET) scans did not show an abnormal lymphatic drainage in the form of enhanced lymph flow or lymphatic obstruction ${ }^{[3]}$.

Another hypothesis is the association between enteropathy and chylous ascites. However, the diagnosis of lupus-associated protein-losing enteropathy relies on characteristic clinical and laboratory features of SLE and on the exclusion of other causes ${ }^{[3]}$. In about two thirds of the reported cases ${ }^{[5]}$, it was also the first manifestation of SLE. Immunologic compromise is common, as seen in our patient, and results in lymphocytopenia, hypogammaglobulinemia and increased susceptibility to infection ${ }^{[2]}$. In our case, protein-losing enteropathy was initially excluded given the absence of typical criteria.

Acute lupus peritonitis was also a consideration, however patients with this complication typically develop acute massive ascites, complain of severe abdominal pain and have evidence of bowel wall thickening on imaging. Chronic lupus peritonitis is a plausible diagnosis. Lymphatic obstruction due to plasmacytic deposits may also be an explanation ${ }^{[4]}$.

The standard treatment for chylous ascites is not yet established. Although most chylous effusions respond to an initial approach with a high-protein and low-fat diet with medium-chain triglycerides, in SLE chylous ascites immunosuppression with high-dose steroids, followed by steroid-sparing therapy has been the most common approach.

Other approaches include frequent paracentesis, surgery (using sclerosing agents and suture ligation of the thoracic duct) or peritoneovenous shunting. Most cases have good outcome, with a relapse rate described in 20-30\% of those associated with protein-losing enteropathy ${ }^{[2]}$. Finally, malignancy may also be a cause since 5 out of the 6 cases reported had positive anti-SSA antibody, which is known to be associated with increased risk of developing non-Hodgkin lymphoma ${ }^{[5]}$.

\section{CONCLUSIONS}

Chylous ascites is a rare diagnosis, even rarer in an autoimmune disease condition. Its causal mechanisms are several and their identification may contribute to a better management. 


\section{REFERENCES}

Sultan SM, loannou Y, Isenberg D. A review of gastrointestinal manifestations of systemic lupus erythematosus. Rheumatol 1999;38: 917-32 Aalami O O, Allen DB, Organ CH. Chylous ascites: a collective review. Surg 2000;128:761-78.

Lee CK, Han JM, Lee KN et al. Concurrent occurrence of chylothorax, chylous ascites, and protein-losing enteropathy in systemic lupus erythematosus. J Rheumatol 2002;29:1330-3.

Dalvi SR, Yildirim R, Santoriello D, Belmont HM. Pseudo-pseudo Meigs' syndrome in a patient with systemic lupus erythematosus. Lupus 2012;21:1463-6.

5. Neto N, Bonfiglioli K, Milanez F. Lymphadenopathy and systemic lupus erythematosus. Rev Bras Reumatol 2010; 50:96-101. 